\title{
Derecho y literatura. Interdisciplinariedad, cruces inevitables y réditos posibles
}

\author{
Law and literature. Interdisciplinarity, \\ inevitable crossings and possible revenues
}

\section{Luis Meliante* y María José Sosa**}

\footnotetext{
* Profesor titular de Filosofía y Teoría General del Derecho, Universidad CLAEH.

凶luimelgar@hotmail.com

** Aspirante en Filosofía y Teoría General del Derecho, Universidad CLAEH.

\mariajosesosa04@gmail.com
}

RECIBIDO: [14.9.2018]

ACEPTADo: [7.12.2018]

\begin{abstract}
Resumen
Se propone al lector explorar en forma introductoria el cruce disciplinar entre derecho y literatura. Se advertirá que la propuesta que se presenta tiene un enfoque interdisciplinario que hace hincapié en las diversas intersecciones constatables entre ambos discursos. Tras una breve referencia a algunos autores que tratan el tema en el espacio regional, se recogen los importantísimos aportes del español José Calvo González, cuya obra desarrolla una teoría y una crítica narratológica del derecho en el marco de una teoría literaria del derecho. Como consecuencia reflexiva, se presentan también insumos teóricos que contribuyen a otra mirada sobre el derecho, expresión de algunos autores que desarrollan las teorías críticas del derecho en la región.
\end{abstract}

Palabras clave: literatura, derecho, Uruguay, análisis literario.

\footnotetext{
Abstract

The reader is asked to explore, in an introductory way, the disciplinary crossing between law and literature.
} 
It will be noted that the proposal presented has an interdisciplinary approach that emphasizes the various verifiable intersections between the two discourses. After a brief reference to some authors who deal with the subject at a regional level, the important contributions of the Spanish José Calvo González are collected, whose work developes a theory and a narratological critique of law, within the framework of a "literary theory of law". As a reflexive consequence, theoretical inputs are also presented, which contribute to "another look on law", as estimated by some authors who develop Critical Theories of Law in the Region.

Keywords: literature, law, Uruguay, literary analysis.

\section{Introducción}

El cruce disciplinar que se constata en las relaciones que pueden encontrarse entre derecho y literatura se ha convertido en centro de interés reflexivo para algunas de las corrientes de las teorías críticas del derecho que se han consolidado en la región. El análisis del derecho como literatura, el derecho en la literatura y el derecho de la literatura es una perspectiva que puede contribuir con otra mirada sobre el derecho, como han señalado algunos de los referentes de la crítica jurídica latinoamericana.

Resultará provechoso realizar una aproximación y explorar algunos autores que se han ocupado del tema, en tanto ha sido escasamente tratado en Uruguay y así, con un punto de vista interdisciplinario, capitalizar aspectos metodológicos y epistemológicos, así como enriquecer el análisis discursivo del derecho. Con este enfoque se advertirá también la relevancia que tiene el hecho de que estas disciplinas se nutran mutuamente de sus diferencias, así como de sus escenarios comunes, aunque de hecho y quizá sin notarlo se transite siempre por este camino vincular.

\section{Derecho y literatura: \\ sus cruces desde una mirada interdisciplinar}

El trabajo que se presenta trata un tema al que no se le ha otorgado la debida atención en la doctrina jurídica especializada uruguaya. Pensar que dos ámbitos de la cultura que parecen tan lejanos se encuentran en relación puede parecer incluso hasta desacertado. Se advertirá por el contrario que el cruce disciplinar que se constata en las relaciones entre ambas disciplinas es centro de interés reflexivo exclusivamente para algunas corrientes del derecho.

Abordar en términos generales el derecho como literatura, el derecho en la literatura y el derecho de la literatura y transitar también por las tesis de la narratología 
jurídica no es sino recorrer categorías de análisis a las que solo puede llegarse a partir de «otra mirada sobre el derecho». Aunque Uruguay ha sido el país en el que menos han repercutido los estudios relativos al relacionamiento interdisciplinar referido, estos se han realizado con insistencia y regularidad en otros lugares del entorno regional.

El abordaje de los vínculos entre ambos saberes tiene una larga tradición, tal como advierten Cárcova y otros (2014, IV), quienes explican que el impacto del denominado giro lingüístico venido desde el centro mismo de la filosofía hacia otras ramas del saber (epistemología, antropología, sociología, psicología, entre otras) repercutió también profundamente en la teoría jurídica. Pone como ejemplo el conocido agrupamiento de autores nucleados en Estados Unidos, en torno al Law and Literature Movement, que comprende, según explica, dos corrientes: law in literature (el derecho en la literatura) y law as literature (el derecho como literatura). La corriente law in literature propone analizar determinadas obras literarias en donde «será posible encontrar referencias, reflexiones y raciocinios, sobre los materiales jurídicos de mayor profundidad y fuerza elucidatoria de la que contienen usualmente los manuales o tratados de derecho» (Cárcova y otros, 2014, IV).

Por su parte, la corriente law us literature estimula realizar el análisis de «categorías desarrolladas en los últimos cien años por la lingüística y la semiótica: la teoría del discurso, la narratividad, la teoría de la recepción y la semiótica del texto» (Cárcova y otros, 2014, IV). De esta manera, tales categorías insertas en el marco de una hermenéutica jurídica «permiten disolver buena parte de los problemas que los juristas discuten desde hace ya muchas décadas» (Cárcova y otros, 2014, IV).

La literatura, como una manifestación del arte que es, aporta la creatividad por excelencia, aprueba la contradicción, genera ficciones, inaugura nuevos escenarios de discusión, promueve la crítica en sentido amplio del término, y de alguna manera ilustra y propicia la revolución del pensamiento apelando permanentemente a lo liberador, o como señalan Magalhães Gubert y Karam Trindade en palabras de Ronald Barthes:

el poder se inscribe, desde siempre, en el lenguaje al que el hombre no escapa pues en ella está inscripto. Y, así, la lengua, entendida como desempeño de todo lenguaje, es fascista, en la medida en que cuando no impide de hablar, obliga a hacerlo. En ese orden, si la ciencia es grosera, de un lado, pero la vida es sutil, del otro, la literatura se revela imprescindible para corregir esa distancia, pues el saber que ella moviliza nunca es completo, definitivo, último, pero tiene la capacidad de cambiar el mundo a través de la subversión de la lengua. (Karam Trindade, Magalhães Gubert, 2009, p. 169)

Lo expresado se inserta en un área compleja de naturaleza epistemológica que refleja el requerimiento de una consideración interdisciplinaria para el derecho que no 
siempre es bien recibida ni valorada, sobre todo desde su campo dogmático. En el presente contexto, con esa expresión sintéticamente expresada, se alude al desarrollo teórico y exposición doctrinaria en determinadas ramas de su conocimiento con pretensión de cientificidad. No obstante, el tema es sumamente cuestionable incluso con respecto a la misma significación que acaba de aportarse.

Resistencias aparte, se estima que la apuesta interdisciplinaria debería ser un lugar común en el campo del derecho, sin perjuicio de que en general es percibida por los juristas con resquemor y lejanía. Pese a ello, el enfoque interdisciplinar del derecho con rol protagónico posibilitaría la humanización de las prácticas interpretativas con una mejor proyección hermenéutica, incluso sin renunciar a su cientificidad para quienes se afilien a esa postura. Por su parte, en la crítica en sentido estricto ${ }^{1}$ del término, que postula otra naturaleza para el derecho, se pretende generar cuestionamientos teóricos que posibiliten discutir entre otras cosas las metodologías de interpretación jurídica arraigadas en los paradigmas tradicionales, teniendo presente que desde esta perspectiva lo que se piensa que el derecho es condiciona necesariamente como este será interpretado (Meliante Garcé, 2017, pp. 847-848).

La relación interdisciplinaria del derecho con otros saberes debería aceptarse sin mayores retaceos, pues aporta «la facilitación de un grado de apertura inusual, especialmente en el campo dogmático, a partir de la cual; y desde la interdisciplinariedad, se podrán apreciar entonces posibilidades y logros acaso impensados (Meliante Garcé, 2003, pp. 12-21).

En el escenario de las ciencias sociales, por ejemplo, estos cruces de caminos son frecuentes y puede decirse que existe un aceptable reconocimiento de la interdisciplinariedad. En este específico ámbito se ha fundamentado en otras ocasiones que el derecho podría integrar el área de conocimiento de las ciencias sociales o por el contrario entenderse - tal como se sostiene en este trabajo- que constituye una práctica social discursiva constitutiva o interviniente y no otra cosa, afirmación que sin duda corresponde aclarar.

Admitir que el derecho es una práctica discursiva, constitutiva o interviniente implica sostener que se materializa específicamente como un proceso social de producción de sentido, porque es a través del sentido en donde precisamente adquiere su especificidad y produce efectos.

Igualmente, tanto en una como en otra de las posibilidades enunciadas, aun en la hipótesis en que se entendiera que el derecho es una particular ciencia social, este se explana y desarrolla a través del lenguaje. Desde la otra perspectiva, sostenida en este aporte y que le atribuye la naturaleza de práctica discursiva, se entiende que la socie-

1 Ver este concepto de crítica en sentido estricto en Meliante Garcé (2014a): «La crítica jurídica Latinoamericana en sentido estricto. De la invisibilidad a su consideración en la Doctrina Nacional», Revista de la Facultad de Derecho, n. ${ }^{\circ}$ 36, Universidad de la República, Montevideo, FCU, pp. 153-184. 
dad en su dinámica de interacción es su escenario y allí este se vehiculiza a través del lenguaje, erigiéndose en discurso con notas especiales. De esa forma, en el contexto social el derecho como discurso reconduce los conflictos intersubjetivos o grupales, que en definitiva son disputas planteadas en función de tramas de poder, con lo que procura la solución de demandas que no han sido satisfechas y que lógicamente tienen distinta naturaleza, contenido y alcance.

Este aspecto, perfilado hacia el análisis del marco lingüístico, discursivo y comunicacional del derecho, es considerado en mayor o menor grado en los distintos núcleos teóricos y doctrinarios de su abordaje iusfilosófico. Si el derecho utiliza el lenguaje o si es en sí mismo lenguaje con tipologías y especificidades diferentes fue parte de un debate mayor que hoy ya se encuentra tamizado. Seguramente, no exista ninguna corriente de pensamiento iusfilosófico que se haya podido sustraer al tema y en donde los problemas lingüísticos y semiológicos que le son inherentes no hayan sido consideradas con mayor o menor énfasis, buscando así dar caudal a sus postulados, preferencias metodológicas e ideologías subyacentes.

Para la versión latinoamericana de las corrientes críticas del derecho que se asume en este trabajo según se adelantara y desde donde se configura el anclaje teórico que constituye su punto de partida, (Meliante Garcé, 2014a; 2016), el derecho es una práctica social discursiva, específica e interviniente. Es práctica pues es un accionar que se sostiene y repite en el tiempo, es social porque responde a la interacción entre los individuos y es específica, porque se distingue de otras prácticas sociales - políticas, morales, económicas, etc. - (Cárcova, 2007, p. 162; Meliante Garcé, 2014a, p. 172). Es además interviniente por ser productora de sentido, y se instala más allá del privilegiado discurso normativo del legislador.

El derecho culmina además, presentándose como una construcción de sentido multívoca, con varios protagonistas: legisladores, jueces, prácticos, administradores, ciudadanos, y también grupos (Meliante Garcé, 2016). De tal manera, el escenario en donde se analizará el tema central de este trabajo —el vínculo entre derecho y literatura- será necesaria e inexcusablemente aquel del marco discursivo del derecho, que se integra de modo espontáneo al ámbito de la comunicación, del relacionamiento intersubjetivo a través del lenguaje y con ello en la producción y adjudicación de sentido. En este escenario influye también el contexto ideológico del cual se nutre el sujeto, pues la reflexión jurídica está siempre de alguna forma inficionada de ideología y en gran medida la adjudicación de sentido y la construcción de una teoría dentro del campo del derecho responden también a ese contenido (Meliante Garcé, 2016), lo que incide de manera radical en la misma experiencia del derecho, tanto en su momento argumentativo previo a la toma de decisión como cuando esta se toma, cuestión que coloca en una posición muy especial y delicada a quienes el Estado ha otorgado la 
cuota de poder necesaria para aplicar el derecho a casos concretos, situación esta que debe ser analizada cuidadosamente.

Por mucho tiempo se sostuvo que el derecho debía mantenerse incontaminado, tesis sobre todo desplegada a través de la obra mayor de Kelsen, que fue y es sin duda la más importante contribución del siglo xx a la teoría general y a la filosofía del derecho. En efecto, la Reine Rechtslehere (teoría pura del derecho) de Hans Kelsen es la obra de filosofía jurídica más importante e influyente en el siglo xx en el ámbito de la ciencia jurídica (en términos kelsenianos), desde los puntos de vista filosófico, epistemológico y metodológico y aportó también rigurosos conceptos en relación con la teoría general del derecho. No obstante, la teoría kelseniana provocó un notorio desplazamiento de la posibilidad del relacionamiento interdisciplinario para el derecho.

En este contexto, se considera valioso distinguir el concepto de interdisciplinariedad del de multidisciplinariedad, tal como lo hiciera Piaget. La interdisciplinariedad refiere al campo de las estructuras profundas subyacentes de los fenómenos comunes que comparten distintas disciplinas. La multidisciplinariedad alude básicamente al trasiego de información entre distintas especialidades (Piaget, 1972). La perspectiva interdisciplinaria acepta que cada disciplina, cada saber — ciencia o no- tenga objetos de análisis en sentido amplio y generalmente metodologías particulares. Esos campos conforman verdaderos sistemas estructurales profundos con elementos, características, finalidades (teleología) propias. Los relacionamientos e interacciones que se generan entre distintas áreas de conocimiento resultan proficuos en general pese a algunos conflictos que puedan surgir y que suelen dirimirse en función de criterios también interdisciplinarios.

Ciertamente el derecho se enriquecería notablemente si se procurase a partir de la interdisciplinariedad un adecuado relacionamiento con otras áreas de conocimiento, en particular aquellas que operan en su entorno, por ejemplo, historia, economía, sociología, política, moral, lingüística, semiótica, psicología, antropología y en el caso por qué no- literatura, sin necesidad de resignar sus centros teóricos y menos su objeto y finalidad, en suma sus estructuras profundas. De no admitirse esta posibilidad, un trabajo meramente introductorio como el que se presenta en este texto no tendría el menor sentido.

El tema, que es epistemológico y también metodológico, culmina atravesando transversalmente todo el derecho, y ha sido analizado en un interesante trabajo de Lea Durante (2008), referido en términos generales a una mirada antropológica acerca de la innegable relación entre derecho del trabajo y literatura, que en Italia ha sido particularmente estudiada. La autora entiende que debe evitarse que este tipo de estudios «abrumen o perturben» la escena del derecho (Durante, 2008, pp. 153-154). Se advierte así un aspecto que resulta especialmente apropiado como para ser generalizado en términos precautorios, casi con el mismo sentido de la buena reflexión que deslizara 
Eco (1975) cuando advertía que debía impugnarse constantemente el modelo de investigación semiótica, a los efectos — decía - de evitar dar la impresión de un imperialismo semiótico arrogante bajo la impronta de una disciplina que pueda abarcar el conjunto de la cultura y descomponerla en signos.

Esta advertencia que debe estar siempre presente puede traducirse en el siguiente apotegma: que lo novedoso no opaque lo riguroso.

\section{Derecho y literatura: una mirada cercana a la región}

El análisis interdisciplinar de la relación entre derecho y literatura comienza a efectuarse en forma sistemática en la década de 1970 para tomar especial intensidad en la década siguiente, particularmente en el horizonte cultural norteamericano. ${ }^{2}$ Por la misma época, movimientos y estudios de esa naturaleza y con el mismo contenido comenzaron a desarrollarse en Europa, en varios países, particularmente en Italia, Francia, España Alemania y Bélgica, entre otros. Bastante tiempo después comenzarán tales estudios en el horizonte cultural latinoamericano.

En Brasil, André Karam Trindade y Roberta Magalhâes Gubert estiman que en la relación entre derecho y literatura, ya sea como derecho contado en la literatura o entendido como un conjunto de narrativas, pese a la notoria difusión de investigaciones y estudios académicos que proliferaron en Estados Unidos y Europa, por lo menos hasta el año 2009, estos estuvieron poco desarrollados en su país (Karam Trindade y Magalhâes Gubert, 2009, p. 166).

No obstante en los últimos años se ha avanzado decididamente en esa dirección investigativa y además de instalarse cursos específicos en el área de grado y posgrado en varias universidades brasileñas se generó un espacio de investigación destacada y conspicua y con permanente actividad académica internacional, como el Coloquio Internacional de Direito e Literatura (CIDIL), que además edita la revista especializada Anamorphosis dedicada particularmente a la temática interdisciplinar que venimos analizando. De tal manera, en ese país, precisamente en el CIDIL y a través de centros universitarios públicos y privados se trabaja intensamente y con logros relevantes en la profundización de investigaciones y aportes sobre el vínculo que se viene desarrollando.

Debe precisarse que el concepto de horizonte cultural es una categoría de análisis creada, con definiciones propias, lingüísticas, culturales, sociales, incluso también antropológicas, etcétera. Sirve para diferenciar en función de esas definiciones, por ejemplo, a gran parte geopolítica de Latinoamérica (el horizonte cultural latinoamericano), que es diferente al horizonte cultural norteamericano (Cobos, 1995; Meliante, 2014a). 
Por su parte, en Argentina la evolución de esta relación epistémica fue examinada por Roggero (2016) en un artículo relativamente reciente al que se hace remisión y en la excelente obra Derecho y literatura. Textos y contextos (2015) que coordinó. Como surge de ese estudio, en Argentina hace años que el tema está instalado.

Hace bastante tiempo entonces que en los países limítrofes se buscan conexiones entre derecho y literatura a influjo de los avances que en Europa y Estados Unidos ya se habían desarrollado desde décadas antes. En Uruguay no ocurre lo mismo, lo que quizá pueda explicarse con los mismos argumentos que sirven para sostener que las teorías críticas del derecho constituyen una corriente minoritaria en la doctrina uruguaya (Meliante Garcé, 2014a).

Los autores que han producido y producen valiosos materiales en el ámbito vincular que se analiza, en general, tienen cercanía teórica con las teorías críticas del derecho en sentido estricto, y desde este núcleo se aprecia con especial interés el estudio de la relación interdisciplinar aludida, la que se transformó notoriamente en una de las categorías de análisis más novedosas en el ámbito de ese movimiento.

De tal forma, el derecho, como forma socio-cultural-discursiva, fue descubriendo nuevos rumbos, en un intento de proveer nuevas posibilidades metodológicas para su acervo. Estos son el resultado de su búsqueda para responder a la incidencia de la visión posmoderna de la realidad así como a la necesidad de disponer de nuevos elementos para confrontar a los paradigmas todavía dominantes en el campo del derecho, particularmente al prevalente positivismo.

En este contexto, lo posmoderno se asume como un concepto comodín, al decir de Eco (2016), que puede aplicarse a multitud de fenómenos de la cultura, entre los que el derecho no queda fuera. Marcó la crisis de los grandes relatos que pretendían ahormar y dar solidez al mundo, y sostuvo además una interpretación, como dice el mismo Eco, «lúdica e irónica del pasado» a lo que se unieron ciertas «pulsiones nihilistas»y probablemente también se encuentre en fase decreciente por su carácter temporal. (Eco, 2016, p. 9, 10). Eso sí, parece haber parido la «sociedad líquida» de la que nos habla Bauman (2004).

Por su parte, se ha entendido que la literatura contemporánea está caracterizada por su fragmentariedad y por tanto resulta pasible de complementariedad en cualquier momento. Tal aspecto es resultado de la evolución de algunos movimientos literarios actuales (esteticismo, naturalismo, realismo, posmodernismo, etc.). Precisamente en el posmodernismo literario es que se presenta con mayor nitidez esta característica, y en donde son relevantes las ideas de falta de certeza y policontextos, lo que hace que la llamada posmodernidad pase a ser concebida en este ámbito no como un nuevo período, sino más como una negación de la modernidad. (Doederlein Schwartz, 2008) 
Se entiende que estas dos características — falta de certeza y policontextos - se han trasladado también al campo jurídico, con la pérdida de la estabilidad promovida como herencia de la modernidad.

Axel Honneth (2009), cuando hizo referencia a la posible instalación de una ética posmoderna y aludió a la opinión en ese sentido de Jacques Derrida, destacó que, en su concepto, la aplicación del derecho en cuanto a su estructura tiene un carácter abierto, hermenéutico y procedimental, y constituye una empresa inacabable, que examina en cada conflicto «aquello que debe tomarse como igual o desigual» (Honneth, 2009, p. 179).

En esta línea entonces, abordaje hermenéutico, teoría de la comunicación, semiología, lingüística e interdisciplinariedad, y por otro lado aceptación de la complejidad social (Luhmann), constituyen el marco más adecuado para dar cuenta del derecho contemporáneo. Desalojarlo de ese entorno conduce a su opacidad (Cárcova, 2006).

En el contexto de la relación entre derecho y literatura, en nuestro escenario regional, constituye un lugar común aludir a los valiosos estudios que sobre el tema realizara el profesor argentino Enrique Marí. Para este autor (1998), la vinculación entre disciplinas aparentemente tan disímiles como literatura y derecho solo puede consumarse cruzando sus fronteras disciplinarias y epistemológicas a través de la conocida metáfora del tendido de puentes entre ambos campos.

De esa manera se establece la necesidad de buscar relacionamientos fértiles entre conceptos, ideas, géneros, disciplinas, esto es particularidades o generalidades de todo tipo desde y hacia el marco disciplinar atinente al derecho, que si bien en principio pueden parecer absolutamente opuestas y contradictorias, en definitiva logran enriquecer su conocimiento poniendo el afán en la búsqueda de convergencias que resulten útiles para allanar dificultades de comprensión (Meliante Garcé, 2014a).

Cuando Marí refirió a la necesidad teórica de tender puentes entre derecho y literatura expresó que esta se hacía evidente al analizar un tema central como lo es la interpretación de los textos jurídicos y literarios. Entendía así que era imperioso referirse a Gadamer en tanto, en su concepto,

la interpretación no es un acto complementario y posterior a la comprensión, pues comprender es interpretar, y la interpretación es la forma explícita de la comprensión, y a su vez la aplicación es un momento integrante del proceso hermenéutico, tan esencial como la comprensión y la interpretación. Comprender es aplicar. (Marí, 1998, p. 261)

Su propuesta efectúa también una revisión de las posiciones antagónicas sobre el punto y cita para ello a varios autores que no aceptan este cruce disciplinar, por ejemplo el neopositivismo de Carnap y toda la corriente del empirismo lógico a la que atribuye gran carga de dogmatismo, pues en este ámbito 
[...] ni el derecho, ni la literatura (o cualquier otra expresión de la estética) tienen la más mínima posibilidad de convertirse en campos sobre los que se pueda construir algo racional, asociando racional con empírico y lógico metodológico. (Marí, 1998, p. 282)

Argumenta además que en función de las posiciones conservadoras de los juristas y el estar sujetos a la influencia del positivismo y del formalismo de la teoría pura del derecho «ha incidido en contra de todo proyecto de interdisciplinariedad, tanto con la sociología como con la moral, la psicología y con la teoría del poder» (Marí, 1998, p. 282).

Por otro lado, el autor destaca la opinión de Ronald Dworkin y sus seguidores, para quienes al ser la interpretación contextual y formar parte del marco interpretativo los principios políticos, tanto de constituciones y leyes, «derecho y literatura marcan los mismos pasos en interpretación, se ponen en la misma fila» (Marí, 1998, p. 283).

Al efectuar un análisis de opiniones afines y disímiles en relación con el tema, Marí se permite concluir con ciertas afirmaciones que describen metafóricamente la opinión de algunos de los autores que menciona. En el caso de Carnap, el tema resulta algo «totalmente vedado»; para Wittgenstein: «de lo que no se puede hablar, mejor es callar»; para Gadamer: «se puede hablar en voz alta [...] con megáfono»; de Dworkin dirá: «se puede hablar en voz alta. La estructura del puente es sólida»; respecto de la Academia del derecho, «le va a costar mucho salir de su estado de "ciego, sordo y mudo"»; y con relación a los hombres de letras y literatos, pese a su desconfianza sobre los juristas: «hombres de negro y cuello de oca», no les costará tanto. (Marí, 1998, pp. 286-287).

Como ya se expresara, en Uruguay el tema estuvo notablemente ausente. Solo pueden citarse algunas insinuaciones al respecto y otros aspectos aledaños (v.g. narrativa jurídica, comunidades interpretativas), como el discurso pronunciado por Oscar Sarlo en la Academia Nacional de Letras (Montevideo, mayo de 2013) sobre el tema «Derecho, literatura y lenguaje. Miradas cruzadas». Por su parte, Luis Meliante abordó por primera vez el tema «Narrativa, ficción y crítica en la ciencia jurídica» en la conferencia de clausura del X Congreso Internacional de Derecho Privado (Punta del Este, octubre de 2013).

Posteriormente, en la Revista Crítica de Derecho Privado n. 13 (Montevideo: La Ley, 2016), el mismo autor trató el tema en el artículo: «De cuando el derecho le hizo un guiño a la literatura y sobre la innegable vigencia y plasticidad de las comunidades interpretativas».

También, Ramiro Castro García, en el V Encuentro Internacional CONPEDI, realizado en la Facultad de Derecho de la Universidad de la República (setiembre de 2016), presentó una ponencia que parte de un modelo analítico propuesto por Botero Bernal, según el cual se toman los discursos jurídicos establecidos en las narrativas literarias 
como objeto del propio derecho, e investiga las relaciones y los límites entre derecho y moral en el romance Lolita, de Vladímir Nabókov, con la perspectiva sustentada por Tony Honoré (cf. Humbert, Humbert: Los límites del derecho y la moral), publicación CONPEDI, módulo Derecho, arte y literatura (Castro, 2016, pp. 7-26).

Finalmente, se publicó en la revista Anales (n. ${ }^{48}$, 2017, pp. 833-863) que edita la Facultad de Ciencias Jurídicas y Sociales de la Universidad de La Plata, en Argentina, el trabajo de Meliante titulado: «Derecho, comunidades interpretativas y movimientos sociales: una fisura en la ortodoxia». Fuera de esas insinuaciones mencionadas, el vínculo entre derecho y literatura y su influjo en torno a la praxis jurídica puede decirse que carece de estudios profundos y sistemáticos, por lo que no ha logrado despertar la curiosidad del campo teórico y menos de la dogmática uruguaya, y probablemente cualquier incursión que se efectúe en el tema se mire con cierta displicencia.

\section{Las intersecciones entre derecho y literatura. José Calvo González, un énfasis en la intersección institucional}

Con la pretensión de presentar de forma más explícita los aspectos vinculares a los que se ha venido aludiendo, se efectuará seguidamente una breve referencia a un completo e inspirador trabajo del profesor de Málaga José Calvo González, autor particularmente conspicuo en el tema que se ha venido exponiendo.

Acude Calvo González (2012) al recurso metafórico de una «mirada al jardín», que resulta ser el espacio enriquecido de la teoría literaria del derecho, cultivado con distintas técnicas y procedimientos y donde la curiosidad instructiva fue siempre compañera de la experimentación, lo que la transforma en un escenario tejido de intersecciones, una geometría de caminos que se entrelazan y que en su caso la conducen a la teoría y crítica narratológica del derecho que, según expresa, interesa menos que las confluencias que se producen para llegar a ella.

De tal forma, la teoría literaria del derecho supone que lo jurídico y lo literario se encuentran en relación. Es decir, que puede inferirse que las posibles líneas

de aproximación y avance de cada elemento de la relación originan encuentros y contactos diferentes [...] de ahí que pudiendo ser diverso el camino por donde marche una determinada idea de Derecho o de Literatura puedan ser también diversos los puntos de intersección que se produzcan. (Calvo González, 2012, p. 299) 
Por otro lado, entiende Calvo González (2012) que cada una de esas posibles intersecciones será diferente y «referirá a una relación en sí misma diferenciada de las demás: el Derecho en la Literatura, el Derecho de la Literatura, el Derecho como Literatura». En cualquier caso, aun cuanto todas ellas atañen a cualidades distintivas acerca de la posible relación derecho y literatura, coinciden no obstante en descartar la transposición o compensación sustitutiva (derecho por o en lugar de literatura), «manteniendo pues el distingo entre los elementos que se relacionan. Ciertamente, es porque Derecho y Literatura se relacionan que Derecho y Literatura se distinguen» (Calvo González, 2012, p. 299).

En cuanto al primer cruce, esto es la intersección que denomina instrumental, dice el autor, que el derecho en la literatura plantea una intersección de tal carácter en recorrido de sentido doble: «el Derecho en cuanto recurso literario, y también la Literatura en cuanto recurso jurídico. En ambos sentidos el carácter instrumental de la intersección revierte en utilidades varias» (Calvo, 2012, p. 302).

Por su parte, el derecho en cuanto recurso literario, es decir, la presencia de lo jurídico en el contexto de la ficción literaria:

contribuye a la formación de los juristas a través del entendimiento sociológico y iusfilosófico de las concepciones de la justicia (por ej., ordalías, talión y venganza, justicia retributiva/principio de conciliación) y del Derecho (por ej., derecho natural/derecho positivo). (Calvo González, 2012, p. 303)

Cuando se refiere a la intersección estructural, el autor efectúa tres posibles puntualizaciones:

I) Se trata de una intersección que resulta un-paso-más-allá de aquella enunciada en términos de Derecho en la Literatura y, en consecuencia, donde la formación jurídico-literaria debida a la lectura no es suficiente, ni tampoco el método exegético de comentario. II) Se trata de un como si o ficción, y III) No se trata de una ficción. (Calvo González, 2012, p. 308)

El profesor español culmina por esa vía argumental estableciendo sólidas bases para la estabilización de una teoría narrativista del derecho, y afirma:

en general para Derecho como Literatura, el principal handicap sigue estando en el poso de incomprensión - a menudo revestido de superioridad doctrinal- que algún tipo de juristas aún opone a la Literatura, y en la renuencia o resistencia tantas veces compartida entre todos - a la elaboración interdisciplinaria (crossdisciplinary) del conocimiento. (Calvo González, 2012, p. 313) 
Finalmente, en cuanto al tercer punto de intersección, a la que denomina institucional, que se abordará en el presente trabajo un poco más detenidamente, el autor estima que derecho y literatura comparten una misma práctica poética.

Ella, expresa Calvo,

no es otra que la efectiva capacidad de instituir lo social, de hacer pasar de la naturaleza a la cultura, de tipificar actos y procesos de sentido compartido, esto es, institucionalizar imaginarios sociales. (Calvo González, 2012, p. 313)

De tal manera, la intersección derecho y literatura que en el derecho con la literatura llama por ese motivo institucional aconseja atender tres puntualizaciones:

I) Que en lo jurídico y lo literario se alojan prácticas sociales instituyentes. II) Que esa dualidad instituyente puede aprovechar del préstamo de ciertas formas literarias de los cánones de poética jurídica. III) Que, por lo que aquí particularmente nos ocupa en interés a una Teoría literaria del Derecho, el propósito es conocer la apropiación por la práctica jurídica institucional de formas arquetípicas de la poética literaria. (Calvo González, 2012, p. 314)

Así las cosas, expresa el autor que: «a) La intersección derecho con literatura no reedita una función instrumental sea en sentido amplio (v.g.: el derecho de la literatura) o estricto (v.g.: el derecho en la literatura/la literatura en el derecho)». Por otro lado: «b) Tampoco reproduce la intersección Derecho como Literatura pues no reincide en paralelos de afinidad mediante estatutos de comparación directa o indirecta». Y también, «c) Es ajena a la transposición o compensación sustitutiva (Derecho por o en lugar de Literatura)» (Calvo González, 2012, p. 314).

Finalmente Calvo concluye en una apreciación de nivel paradigmático en el marco del cruce institucional, al afirmar que «Los vectores jurídico y literario de la intersección Derecho con Literatura se hallan en una relación (Derecho y Literatura) de paraigualdad» (Calvo González, 2012, p. 314).

De esta forma, en una mirada hacia su interior, queda instalado un relacionamiento democrático derivado del cruce disciplinar (paraigualitario) que implica por consecuencia un sentido también democrático de sus resultados, dando por tierra con el posible predominio institucional hegemónico que el discurso del derecho normalmente se arroga. Esta democracia de sentido paraigualitario, se correrá luego también - como se verá- hacia el marco discursivo interno de la composición multívoca del discurso del derecho.

Por otro lado afirma que la oportunidad y marco de discusión de esta intersección institucional tienen como referencia los retos planteados al derecho: 
[...] por la crisis del paradigma jurídico de la modernidad y que en Literatura se remontan al paradigma de la relación texto-lector en las escuelas estructuralistas y de las teorías del Textlinguistic. (Calvo González, 2012, p. 314)

Los juristas participaron siempre de alguna manera (como insiders) de este proceso de apropiación de la literatura por el derecho, aún en el momento de la instalación del paradigma codificador, deriva del positivismo hoy en crisis (Calvo González, 2012). Pero veamos esto un poco más profundamente, la relación de la díada derecho y literatura culmina de alguna manera exponiéndose como «derecho con literatura», en donde se cuenta con un protagonista como lector privilegiado de la escritura social: el legislador.

Este peculiar agonista superpuesto como lector de la trama del tejido social «escribe en una parte lo que estaba escrito en otra [...] dándolo luego en lectura» (Calvo González, 2012, p. 315). Pero, lo peculiar es que este lector privilegiado logra transportar a sus destinatarios de una manera intensa y penetrante su lectura, con una colocación física poderosa que se concreta en el codex (Código), libro escrito del derecho, emblema de la textualización y reducción del derecho a lo escrito en el Código. La forma del derecho — dice el autor (2012) - es la forma de la escritura jurídica en el sentido que se ha venido expresando, es también la escritura pública del derecho.

Esa forma de traslación y transcripción - reductiva- del derecho a lo escrito en el Código, cuyo reconocimiento se encuentra en la Constitución, opera además en concierto con una Grundnorm (NHF, norma de clausura del sistema propuesto por Kelsen) y que es clausura del sistema jurídico en su totalidad. En su recorrido de arriba hacia abajo y de abajo hacia arriba busca y otorga validez a las normas colocadas dentro del sistema, pero también es muestra de soberanía jurídico-política (Calvo González, 2012).

Este modelo, explica el autor (2012), está en crisis. Más que en el tiempo de la codificación, nos encontramos en el tiempo de la decodificación. La forma piramidal kelseniana se ha truncado. El derecho en la posmodenidad es más que una pirámide, una meseta o mil mesetas (Gilles Deleuze - Félix Guatari). El emblema de esta geografía jurídica milmesetaria es —dice Calvo- «la complejidad y su signo la red». El rizoma, en palabras de Ost, que reformula la centralidad y la estabilidad jurídico-productiva, acogiendo multiplicidad de centros y movilidad (Calvo González, 2012, p. 316).

El desafío de la relación derecho y literatura, finalmente plasmada en la díada «derecho con literatura», será renovar «críticamente el enfoque de la vieja textualización jurídica en tres niveles: relectura, reescritura y oralización del Derecho» (Calvo González, 2012, p. 316).

La relectura implica una reinterpretación del sentido del texto. De tal manera que en tanto la decodificación implica problemas de comunicabilidad del texto 
hacia sus destinatarios, se irán en busca de un código pero en el sentido de «derecho que habla a todos». (Calvo González, 2012, p. 317)

En cuanto a la reescritura, esta implica varias dimensiones: a) La reescritura como aceptación de las transformaciones operadas en las categorías-monopólicas de autoría del texto, abriéndose hacia la concurrencia de otros poderes-autores. Textos legales y textos jurisprudenciales deben aparecer en un nivel de paraigualdad. Implica ello una reescritura de la teoría de las fuentes del derecho. $b$ ) La reescritura del género del autor de la escritura del derecho, que tradicionalmente se escribió desde el género masculino, hoy deberá reescribirse como un «derecho para dos». c) La reescritura como operación material deberá dar entrada a los procesos de escritura informáticodigital del derecho escrito, para posibilitar una «renovada comprensión de los agentes y funciones codificadora» (Calvo González, 2012, p. 318).

Finalmente, la oralización implica una inversión de la tradicional relación con el texto cuyo presupuesto era la escritura de la palabra hablada. Ahora se trata de la oralización de la palabra escrita. El tránsito a la oralización,

[implica un acortamiento de la distancia entre derecho escrito y derecho oral [...]. Se ha demostrado con la modificación de las legislaciones procesales penales y administrativas, en donde se han rehabilitado las competencias retóricas y técnicas de la litigación adversarial, [...] participantes en la sustanciación de los procedimientos judiciales. (Calvo González, 2012, pp. 318-319)

La oralización, además, atiende los fenómenos que se relacionan con esta dentro de la problemática del lenguaje jurídico, y se vuelca sobre la redacción lingüística de productos legislativos. También opera en función de la traducción del derecho escrito protagonizado por el abogado como figura medial entre diferentes lenguajes: pasa el mensaje desde un lenguaje extralegal o extrajurídico del cliente o patrocinado a uno legal o jurídico (judicial), y nuevamente a uno extralegal o extrajurídico del cliente o patrocinado.

Puede verse así que desde el marco narrativo del derecho se aporta la metáfora del rapsoda, en razón de la tendencia actual hacia la forma oral de organización y transmisión del pensamiento. La rapsodia mitiga, según Calvo (2012), la futilidad, urgencia y proliferación productiva, que suele provocar archipiélagos textuales, con la consiguiente pérdida de fuerza performativa. De esta manera, frente al declive del paradigma vigente - según se viera - el jurista-rapsoda, en el marco narrativo, construye el derecho tejiendo relatos con relatos de otros, y aprovecha la hibridación de escritura-oralidad, para pulir la indeterminación, borrosidad, flexibilidad, etcétera, de algunos conceptos jurídicos. 
Por ende, la relación derecho y literatura, plasmada en la categoría summa, derecho con literatura, a través de la combinación de los niveles de relectura, reescritura y oralidad, es posiblemente según el autor,

el más idóneo enfoque para llevar a cabo un control eficiente de la diversificación reticular cuyas irrevocables fuerzas centrífugas degenerarían en la destrucción de la idea de orden jurídico. En general también esta opción supone una decidida ruptura epistemológica y profunda re-habilitación jurídica. (Calvo González, 2012, p. 321)

Como puede verse, el tratamiento que hace el autor español a través del estudio de la tríada de intersecciones que vincula derecho con literatura, sin duda efectuado con enriquecedora puntillosidad, deja en evidencia insoslayable el vínculo que liga a ambos saberes. Se erige sí en predominio vincular, la intersección «institucional» en términos de paraigualdad disciplinaria. Por ello se ponderó su análisis.

Que se profundice esto desde el campo de cualquiera de ambas disciplinas transitando del derecho a la literatura, o de la literatura hacia el derecho, dando cauce al recurso interdisciplinario, queda como un requerimiento de sus respectivas dimensiones pragmáticas y epistemológicas, no exento de sano sinceramiento, sobre todo para el derecho.

\section{Proceso, narrativas y ficciones}

El cruce disciplinar entre derecho y literatura refiere a una contextualidad propia y sumamente beneficiosa para ser estudiada. Esta transita, como se analizó, por diferentes abordajes, entre los que se han señalado de modo general como dominantes en la actualidad, aquellos que, como argumenta Soler Bistué (2011), son los provenientes del campo del derecho que proceden a describir y estudiar sus representaciones en testimonios literarios (derecho en la literatura) o, por el contrario, proceden a examinar la cualidad literaria del derecho tomando como formas literarias distintas sentencias judiciales y para ello se busca el auxilio en teorías de la literatura y el análisis de las formas narrativas (derecho como literatura), finalmente nucleados, como se vio, en la categoría summa de derecho con literatura, en la que ambas disciplinas funcionan en correspondencia y en una democrática relación paraigualitaria.

Desde el punto de vista de la estilística literaria, una de las formas notorias en que se consolida el cruce disciplinar analizado es el marco narratológico que necesariamente concierne al derecho por inherencia.

Posadas Garcés analiza las formas de mimesis en las que se anclaría la composición narrativo-literaria en los diferentes ámbitos del discurso jurídico desde una pers- 
pectiva hermenéutica conforme a la opinión de Paul Ricoeur en su obra Tiempo y narración (Posadas Garcés, 2010), y que se consumarían con intensidad variada en una temporalidad diferente y bajo tres formas nítidas: $a$ ) la que emerge de la denominada por Ricoeur mimesis I, relativa al derecho sustantivo en el que se encausará el proceso, y que revela la pre-comprensión del actuar humano que constituirá la trama de las acciones que se controvertirán en el debate judicial; $b$ ) la que emerge, según el autor, de la mimesis II, constituida por la narración con la que comienza cualquier proceso judicial, sea en forma escritural u oral, pues cualquier parte que ingresa a la escena del proceso debe comenzar narrando las acciones que dan lugar al conflicto judicial. Lo mismo acaece con la parte que es demandada o acusada, según sea la naturaleza procesal de la causa, de manera tal que cada parte organiza un relato histórico cuya trama debe guardar clara correspondencia con la facticidad y normatividad que sustenta la mimesis I, (Posadas Garcés, 2010); y c) siempre se encontraría la que emerge de la mimesis III, pues la narración cobra su pleno sentido con el acto judicial final de la sentencia o adjudicación, que dicta un sujeto que forma parte del elenco narrativo y que necesariamente involucra en su narración, también histórica, a los episodios narratológicos anteriores de las mimesis I y II.

En la doctrina uruguaya, en sintonía por lo menos relativa con este criterio, se consideró necesario

mostrar la intrincada correspondencia que existe en la trama interna del derecho, entendido literalmente como un relato narrativo en el que conviven una multiplicidad de otras especies de narraciones, entre ellas el recurso a las ficciones, potente y performativo, que nacido en los albores del derecho romano y consumado más orgánicamente a partir del derecho pretoriano y de ahí en más, se ha adherido fuertemente al derecho latino contemporáneo. (Meliante Garcé, 2014b: 5)

Dentro de las posibilidades narratológicas que se han considerado del derecho como literatura, tipicidad propia de derecho con literatura, toma especial relevancia aquella que produce y reproduce el relato de los jueces. Como se ha expresado (Espinosa, 2004), la lectura literaria de la jurisprudencia de los tribunales en cualquier grado permite ver como el relato de una voz particular que se concreta en la demanda social de un sujeto entendido sin exclusiones se transforma en las voces del juez o de los jueces que se materializan en sus decisiones tomadas simbólicamente dentro del recinto del tribunal, como verdaderos palimpsestos, y se desdoblan en múltiples componentes. De ahí su polifonía. Se recogen así distintas voces que cuentan y dan lugar a una voz general, a un nuevo relato social que asume la ruptura de la diglosia, un relato privilegiado de la separación entre la voz del poder y la voz del pueblo (Espinosa, 2004). 
Como ejemplo particularizado entre los tantos que pueden ser estudiados en torno a la temática vincular que se ha venido desarrollando, se ha seleccionado en forma absolutamente arbitraria uno que se comentará brevemente, y que da cuenta de una de las tantas narrativas relacionadas con sentencias de la jurisprudencia laboral de Uruguay que releva uno de los denominados temas de identidad corporal. Esta temática general, estudiada en forma pormenorizada por Espinosa (2004), trata de una categoría que comprende demandas sociales que, como se ve en el caso que se toma de ejemplo, se concreta en una pretensión laboral (aunque también pueden especificarse claramente en otro tipo de jurisdicción), y en general se encuentran referidas a la protección indistinta de la maternidad, derechos de la salud, modificaciones corporales, sexualidad, género, autoimagen, autonomía procreativa o discriminaciones por razones de sexualidad, género, transgénero, raza y muchas otras de similar naturaleza.

Sin perjuicio del discurso legislativo vigente en Uruguay, que en muchos de esos temas particulares se ha actualizado en forma relativamente reciente y colocó al país en lugar de mención en ese sentido, debe decirse que la utilización de tal discurso legis-normativo por parte de los tribunales uruguayos va siempre acompañada desde el propio tribunal por una verdadera composición narrativa que en general suele potenciar socialmente en forma notable de forma prospectiva y hacia el imaginario social el contenido pretensivo de esos tipos de demandas. También operan con contenido hermenéutico hacia la interna comunitaria interpretativa del derecho, sobre todo hacia la jurisprudencia (Meliante Garcé, 2017). La lectura de tales tipos discursivos, desde el punto de vista de la teoría literaria particularmente narratológica, permite percibir algunas rupturas fuertes en el marco del discurso judicial, que logran introducirse en aspectos generalmente vedados del propio discurso social que refieren al tratamiento del tema enjuiciado. En cierto modo, la narración judicial termina, implícita o explícitamente, reconstituyendo narraciones ya instaladas en el imaginario social, así como en los núcleos comunitarios interpretativos internos, acerca de esas mismas identidades corporales, tal que puede inferirse del texto que se aportará.

Como se apreciará seguidamente, se trata de un caso de despido abusivo en el que la parte actora alegó haber sido objeto de trato discriminatorio por haber soportado física y emocionalmente destrato y humillación por parte de sus supervisores, por la condición de ser de raza negra. La parte demandada que negara desde el comienzo tal relato así como la imputación jurídica, luego de la primera instancia que hizo lugar al reclamo, se agravió de la configuración del despido abusivo y la recurrió. Por su parte, la actora hizo lo propio con relación a la cuantificación de este. El tribunal de alzada confirmó la sentencia de primer grado en el primer aspecto, al entender que efectivamente hubo despido abusivo y acogió también el agravio de la actora, condenando al demandado a abonar una suma relativamente importante. 
Vemos la especie narrativa que se configura en el acto decisorio. Expresa el tribunal:

Los hechos invocados por los contendientes, evaluada su prueba bajo la guía de la distribución de las cargas probatorias enunciadas, teniendo en cuanta muy especialmente que la accionada no probó que despidió a la trabajadora por las razones que había invocado - bajo rendimiento - arrojan con margen de altísima probabilidad que, como planteó la demandante, la empleadora puso fin a la relación de trabajo, arbitrariamente por su mera condición de ser de raza negra. Vale decir que la privó de su derecho al trabajo discriminándola, dándole un trato perjudicial en relación a su empleo, por ser negra. Actitud que califica el despido como conculcatorio del derecho a la no discriminación por razón de color de piel anulando el derecho a recibir un trato igualitario respecto de otros empleados. En efecto. En el caso, la empleadora anuló el derecho a la igualdad de trato de la trabajadora hiriendo gravemente su dignidad laboral. La igualdad es condición de la dignidad. «Por eso, la desigualdad no justificada agrede la dignidad. La dignidad es incompatible con la desigualdad injustificada», «El objetivo de la no discriminación no es la igualdad entre capital y trabajo, sino la eliminación de diferencias injustificadas entre trabajadores...» (Ermida Uriarte, Oscar. «Meditación sobre el Derecho del Trabajo». Cuadernillos de la Fundación Electra. N. 1. FCU. Montevideo, 2011, pág. 13). Resultó acreditada la persistente actitud persecutoria de dos encargados de turno y superiores de la actora, XX y NN, consistente en expresiones agraviantes por su raza negra. Sumado a ello y por parte del primero, la conducta discriminatoria expresada además en la adjudicación arbitraria de tareas más gravosas, pesadas e especialmente injuriantes para su dignidad y estado físico, ilustrativas todas de un trato distinto, vejatorio e hiriente a la trabajadora. ${ }^{3}$

La utilización del recurso interdisciplinario del que se ha venido dando cuenta hace posible entre otras cosas como se ve —más allá de la composición discursiva común al estilo formalizado y forense- que se aprecie el uso simbólico del derecho, o sea sus expresiones de sentido y sus representaciones, en definitiva, las formas en que una sociedad exterioriza una forma de respeto al derecho (Doederlein Schwartz, 2008). En el caso ejemplificado, como puede apreciarse, se vincula la cuestión a un set de lenguaje tropológico cuyo nexo es un vasto foro de principios: igualdad, dignidad,

3 Se trata de parte del texto de una sentencia de segunda instancia publicada en la web de la Base de Jurisprudencia Nacional, dictada por el Tribunal de Apelaciones del Trabajo de $1 .^{\mathrm{er}}$ Turno, con fecha $1 .^{\circ}$ de agosto de 2012, autos: P. M. Ma. c/ E... S.A. Desp. abusivo, despido injusto, d y p, multas. IUE 2 $100.799 / 2011$. 
no discriminación, etcétera, con connotación constitucional, incrementando en una proyección prospectiva, el marco argumentativo de la demanda inicialmente promovida.

Desde otro ángulo, aunque no ya explícitamente en el texto, se puede apreciar también que en el contexto de las tramas narrativas jurídicas que funcionan en sintonía de paraigualdad con las literarias, emerge un centro de enunciados ficcionales poderosos, sugestivos y a los que debe atenderse con especial esmero.

Expresa Calvo González que desde la perspectiva del derecho con literatura, la cuestión de las ficciones en el espacio jurídico debe partir de dos postulados que son: a) un texto ficcional (por ejemplo una ficción legal) que no está llamado a divergir lo real, sino a hacer compatible una imaginable confluencia con él, puesto que una ficción legal puede coincidir con lo real, y $b$ ) que el argumento de que existan ficciones más cercanas a la realidad que otras tampoco debería llevar a reducir lo ficcional solo a lo irreal, porque ello significaría confundir los efectos reales de la ficción con la ficción misma (Karam Trindade y Karam, 2018). Así, es posible afirmar que, en su contextualidad narratológica, el derecho está atravesado por un plano profundamente ficcional que se traduce en enunciados potencialmente inverificables, muchas veces alejados también de la experiencia y de cualquier procedimiento formal demostrativo, pero que pese a ello poseen una potencialidad performativa, modificativa de la realidad y comúnmente son aceptados sin cuestionamientos por quienes operan en la praxis jurídica. (Meliante Garcé, 2014b). El como sí de Hans Vahinger desborda claramente en la plana ficcional del derecho.

En el derecho uruguayo, como parte de la herencia cultural de la modernidad, se ha aceptado también esta tradición ficcional legalizada sin muchos reparos, como consecuencia de su inserción en la cultura jurídica latinizada y en función de dos grandes conceptos generales que provocan su clara legitimación: a) aquel que establece que todos los hombres son iguales ante la ley (art. 8 de la Constitución de la República), y $b$ ) aquel que indica que el derecho se reputa por todos conocido, en los términos consignados en el inciso $3 .^{\circ}$ del art $1 .^{\circ}$, y en el art. $2 .^{\circ}$ del Código Civil uruguayo, a los que se suma un vasto sistema ficcional que fue incorporado al derecho del país. Son un claro ejemplo de ello las ficciones aprobadas en categoría de fictio legis, de la teoría de los comorientes, de la categoría de persona jurídica, de la condición de inmuebles por accesión atribuida a ciertos bienes muebles, de la teoría de la cosa juzgada, de la calidad de ausencia con presunción de fallecimiento, el otorgamiento de la condición de validez o invalidez a una situación o a un acto, incluso retrotrayendo sus efectos, en función del transcurso del tiempo, etcétera (Meliante Garcé, 2014b).

En el último tramo de lo que viene de exponerse en forma acotada, se ha hecho referencia a un elenco de las denominadas ficciones legales. No obstante, no puede perderse de vista que es esto lo que sucede con el derecho en su totalidad porque, como bien dice Calvo González, resulta poco discutible que el deber ser que el derecho 
postula con notoria regularidad ni es verdad ni lo contrario, y además esa ficción de un deber ser se dirige a producir un efecto de realidad en el mundo real imaginándolo, pero imaginándolo como si fuera efectivamente real (Karam Trindade y Karam, 2018).

Puede decirse así que aquella mimesis I de la tríada diseñada por Ricoeur, y que el autor coloca al comienzo del discurso del derecho a partir del contexto normativo sustancial que resulta pre-comprensivo de lo que vendrá luego en el curso del proceso, es sin duda resultado también de un pacto narrativo que logra producir un efecto de realidad en el mundo real, a través de un deber ser normativo que se imagina como efectivamente real y que opera como una fábula narrativa que aspira a tener un efecto pragmático al margen de su valor de verdad (Karam Trindade y Karam, 2018).

Sin duda lo expresado constituye tan solo una muestra que corrobora lo argumentado en torno a la inexcusable naturaleza narratológica que se edifica en los episodios y tramas del discurso jurídico.

Quedan por el camino otras reflexiones que van en el mismo sentido, como, por ejemplo, un análisis más detallado del tópico consecuente con la estructura retóriconarrativa que tiene el propio proceso jurisdiccional como conjunto de actos sucesivos predeterminados y que resultan equivalentes en su performance a una escena o una secuencia de ella, en las que no son ajenas las dotes de improvisación de sus protagonistas. El momento culminante de ese itinere procesal, esto es su escena final, es un acto como se vio decisorio y adjudicativo, también esencialmente histórico, narrativo, claramente expositivo y reconstructor del pasado, para otorgarle un sentido a lo pretérito, inficionado de ineludible composición ficcional y metonimia. Este acto tiene a un único y peculiar protagonista con un claro y legítimo poder de clausura escenográfica otorgada por el Estado: el juez (Cárcova, 2006; Meliante Garcé 2014b).

\section{Conclusiones}

En el presente trabajo se han tratado aspectos relevantes necesariamente vinculados al tema central convocado pese a que la propuesta no deja de ser en algún sentido meramente descriptiva y por sobre todo introductoria a un tema muy poco o poco transitado en Uruguay. Que no caiga en lugares hueros no responderá claramente tanto a la bondad de lo que aquí se ha expresado sino a la aceptación de las claves propuestas para su tratamiento: una epistemológica y metodológica, y discursivonarrativa la otra.

Como breves conclusiones, se estima que:

a) En primer lugar se entiende - por sobre todas las cosas- que el derecho debe abrirse a la interdisciplinariedad. Fundamentos para sostener ese aserto pueden encontrarse de manera explícita y también implícita en este trabajo. 
b) En este escenario, que es un abordaje con incidencias epistemológica y metodológica, se encuentra inserta la proficua relación que se ha presentado entre derecho y literatura, aunque deberá tenerse presente la notoria escasez de estudios a este respecto en la doctrina especializada uruguaya.

c) Queda en evidencia también, con una apreciación crítica en el sentido que se ha capitalizado en el texto, que el trasfondo discursivo-narrativo del derecho, por lo menos en determinadas fases pragmáticas de su materialidad, es insoslayable y obliga a revisar constructos teóricos interpretativos de nivel paradigmático y todavía prevalentes.

d) La investigación de Calvo González, que deja traslúcida de manera acabada la red de intersecciones e hibridaciones entre ambas disciplinas, y la ponderación que se hace en este trabajo de la intersección institucional trabajada en profundidad por el autor español dan cuenta de la potencialidad enriquecedora del relacionamiento entre ambas , desde el punto de vista epistemológico y metodológico.

e) Deben surgir proyectos de investigación futura, que meramente pueden insinuarse a partir de las acotadas reflexiones que se expusieran. La conocida metáfora dworkiana de la connotada novela en cadena, que aborda el marco interpretativo y creativo comunitario del derecho, transitada también desde otra perspectiva por Stanley Fish y otros, da cuenta de que es precisamente ese campo en el que la relación interdisciplinaria entre derecho y literatura resulta sin duda fecunda y relevante. También en el marco de una teoría narratológica del derecho, los estudios encaminados por Calvo González de los que se ha dado cuenta serán ineludibles, en tanto, además de revelar la naturaleza interna ficcional del derecho, ayudan a comprender el interior mismo de la naturaleza profesional de quienes ejercen su praxis. Por su parte, el análisis de los temas atinentes al derecho que son también los de la literatura: vida, muerte, drama, accidentes, trabajo, alienación, arte, delito, venganza, poder (Posner), al formar parte de la experiencia humana, resultaría enriquecido por la relación interdisciplinar. La necesaria perspectiva de humanización del derecho que puede ser lograda a través del razonamiento literario y el descubrimiento de determinadas coordenadas éticas capitalizables desde determinados géneros de la literatura (Nussbaum) constituyen otro eje de fecundas indagaciones. Por otro lado, trasladar estos estudios desde el marco legis -iuris - narrativo, al corazón mismo de la Constitución para la creación sólida de una eventual teoría literaria de la Constitución (Calvo González), que tome como eje histórico de construcción literaria el pacto fundante de todo Estado, al pairo de la Grundnorm y con ella de su lógica ficcional, es sin duda otro desafío hermenéutico (Ost) estimulante. En fin, queda mucho por hacer aún.

Que los juristas contemplen y analicen estas circunstancias ayudaría en mucho a la comprensión de los problemas que impactan directamente en la praxis del derecho. 
Tal actitud no es otra cosa que pensarlo de manera diferente y posibilitar su abordaje a partir de otra mirada e instalar nuevos escenarios de discusión.

\section{Bibliografía}

BAUMAN, Z. (2004). Modernidad líquida (3a. ed.). Buenos Aires: FCE.

CAlvo GonZÁLEZ, J. (2012). El escudo de Perseo. La cultura literaria del derecho. Granada: Comares S.I.

CÁRcova, C. M.a (2006). La opacidad del derecho. Madrid: Trotta.

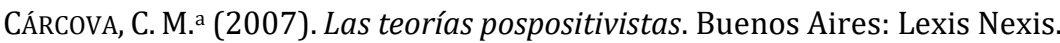

CÁRcova, C. M. a, Douglas Price, J., y RuIZ, A. (2014). La letra y la ley. Estudios sobre derecho y literatura. Buenos Aires: Ministerio de Justicia y Derechos Humanos de la Nación Argentina.

CASTRO, R. (2016). «Humbert, Humbert: Los límites del derecho y la moral». En A. KARAM TRINDADE, R. L. NERY DA Silva (coords.), Direito, arte e literatura. Florianópolis: CONPEDI. Recuperado de: https://www.conpedi.org.br/publicacoes/ 9105o6b2/6114p753/BMv5zX1f5NpP38ch.pdf.

Coвos, J. (1995). América Latina, Madrid: Acento.

Constitución de la República Oriental del Uruguay (1967). Asamblea General, Montevideo, Uruguay, 24 de agosto de 1966.

División Estudios Legislativos. CÁmara de Senadores (2010). Código civil: Actualizado al 26 de febrero de 2010, https://parlamento.gub.uy/sites/default/files/CodigoCivil201002.pdf?width=800\&height=600\&hl=en_US1\&iframe=true\&rel=nofollow.

DoEDERLEIN SCHWARTZ, G . (2008). «Um admirável novo direito: autopiese, risco e altas tecnologías sanitarias. En Direito \& literatura. Reflexôes teóricas (pp. 192-208). Porto Alegre: Livreria do Advogado.

DURANTE, L. (2008). «Era globale e mutazione antropológica: la "vita messa al lavoro" e le forme del narrare». En Lavoro, diritto e letteratura italiana (pp. 153-170). Bari: Cacucci.

Eco, U. (1975). Tratado de semiótica general. Barcelona: Lumen.

Eco, U. (2016). De la estupidez a la locura. Crónicas para el futuro que nos espera. Barcelona, Lumen.

ESPINOSA PÉREZ, B. (2004). «Narraciones en el campo jurídico». Universitas, 108, 690709, Bogotá: Pontificia Universidad Javeriana.

Honneth, A. (2009). «Lo otro de la justicia. Habermas y el desafío ético del posmodernismo». En Honneth, A. Crítica del agravio moral. Patologías de la sociedad contemporánea, Buenos Aires: Fondo de Cultura Económica. 
Karam Trindade, A., y Karam, H. (eds.). (2018). Por dentro da lei. Direito, narrativa e ficçao. Rede brasileira direito e literatura. Florianópolis: Tirant lo Blanch.

Karam Trindade, A., y Magalhães Gubert, R. (2009). «Derecho y literatura. Acercamientos y perspectivas para repensar el derecho». Revista del Instituto de Investigaciones Ambrosio L. Gioja, año III, 4, 164-213. Buenos Aires: Departamento de Publicaciones, Facultad de Derecho, EUDEBA.

MARí, E. (1998). «Derecho y literatura. Algo de lo que sí se puede hablar pero en voz baja», DOXA, 21, II, 253-287.

MELIANTE GARCÉ, L. (2003). Semiótica y derecho penal, aproximación interdisciplinaria y vinculación con la práctica. Montevideo: Carlos Álvarez.

MELIANTE GARCÉ, L. (2014a). «La crítica jurídica latinoamericana en sentido estricto. De la invisibilidad a su consideración en la Doctrina Nacional», Revista de la Facultad de Derecho, 36, 153-184. Montevideo: FCU.

MELIANTE GARCÉ, L. (2014b). «Narrativa, ficción y crítica en la Ciencia Jurídica». Revista Crítica de Derecho Privado, 11, 3-19, Montevideo: La Ley - Uruguay.

MEliante GARCÉ, L. (2016). «De cuando el derecho le hizo un guiño a la literatura y sobre la innegable vigencia y plasticidad de las «comunidades interpretativas». Revista Crítica de Derecho Privado, 13, 3-33. Montevideo: La Ley - Uruguay.

MELIANTE GARCÉ, L. (2017). «Derecho, comunidades interpretativas y movimientos sociales: una fisura en la ortodoxia». Anales, 48, 833-863, Facultad de Ciencias Jurídicas y Sociales de la Universidad de La Plata, La Ley-Argentina.

PiagET, J. (1972). «L'épistémologie des relations interdisciplinaires». En L'interdisciplinarité: problèmes d'enseignement et de recherche dans les universités (pp. 131144). París: OCDE.

PoSADAS GARCÉS, J. P. (2010). «Derecho y narración. El carácter triplemente mimético de juridicidad». Co-herencia, 7 (12), 199-210, enero, Medellín.

Roggero, J. (2015). Derecho y literatura. Textos y contextos. Buenos Aires: Departamento de Publicaciones de la Facultad de Derecho, EUDEBA.

RogGERo, J. (2016). «Hay derecho y literatura en Argentina». Revista Internacional de Derecho y Literatura Anamorphosis, 2(2), 269-292, Red de Derecho y Literatura. Recuperado de: seer.rdl.org.br/index.php/anamps/article/view/293.

SOlER BISTUÉ, M. (2011). «Derecho, narración y racionalidad jurídica. El caso de la "fazaña” bajomedieval». Cuadernos Electrónicos de Filosofía del Derecho, 22, 162 189. 